\title{
THERMOANALYTICAL STUDY OF THE PESTICIDE 3-AMINO-1,2,4-TRIAZOLE
}

\author{
P. J. Sánchez-Soto, E. Morillo ${ }^{\mathrm{x}}$ J. L. Pérez-Rodríguez and \\ C. Real
}

Instituto de Ciencia de Materiales, Centro Mixto Consejo Superior de Investigaciones Cientificas, Universidad de Sevilla, Apdo. 1115, 41080-Sevilla, Spain

Instituto de Recursos Naturales y Agrobiologia, Consejo Superior de Investigaciones

Científicas, Apdo. 1052, 41080-Sevilla, Spain

\begin{abstract}
Thermoanalytical study of the pesticide 3-amino-1,2,4-triazole (ATA) has been carried out, using simultaneous DTA-TG in nitrogen flow, in order to know its thermal behaviour and stability. These techniques have been further complemented using evolved gas analysis and mass spectroscopy (EGA-MS). Two different stages of ATA decomposition were observed: after the first decomposition step, a mixture of compounds is obtained, according to MS data, being the principal component a compound of molecular weight 126 . It is formed by a first order reaction mechanism, according to the kinetic study, with $E_{\mathrm{a}}=124 \pm 8 \mathrm{~kJ} \cdot \mathrm{mol}^{-1}$. The second decomposition step takes place about $735^{\circ} \mathrm{C}$, with evolution of $\mathrm{HCN}$ and $\mathrm{NH}_{3}$, being the final weight loss $96 \%$.
\end{abstract}

Keywords: DTA-TG, EGA-MS, kinetic, pesticides

\section{Introduction}

The pesticide 3-amino-1,2,4-triazole (named amitrole, ATA, Weedazol, cytrol, amizol) was the first 1,2,4-triazole to be manufactured on a large scale from aminoguanidine formate. It is a non-selective herbicide which inhibits chlorophyll formation and regrowth from buds. Although some derivatives are more effective for some purposes, none of the more complex triazole derivatives has been able to displace aminotriazole as a neutral herbicide and defoliant of cotton. This pesticide is a basic compound that is able to protonate in aqueous solutions depending on the solution $p H$, since the $p K$ is 4.14 . It occurs in two desmotropic forms (I and II, Scheme 1); 3-amino-1,2,4-triazole is in the form (I) and its salts in the imino form (III).

In our laboratory, we are currently involved in some research projects on environmental problems concerning pesticides and their application in Andalusian (South Spain) agricultural soils. Some investigations on the adsorption of ATA 
by the clay mineral montmorillonite have been carried out [1]. It was found that a montmorillonite-ATA complex is formed through interlamellar cations, the adsorption mechanism depending on the clay exchangeable cations. Under another point of view, ATA is also an interesting compound in materials science, since it has been proposed as raw material in the synthesis of ferromagnetic materials through formation of binuclear complexes [2]. However, the thermal behaviour of ATA alone is little understood.

\section{Scheme 1}

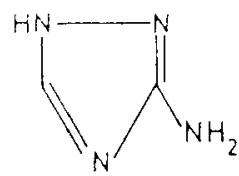

(1)

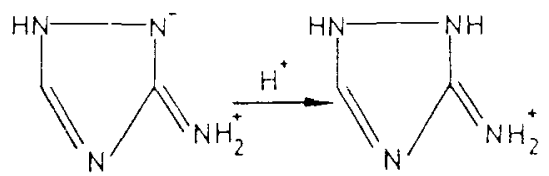

(II)

(III)

In the present investigation a thermoanalytical study of ATA has been carried out, using simultaneous DTA-TG in nitrogen flow in order to know the thermal behaviour and stability of ATA. These techniques have been further complemented using evolved gas analysis and mass spectroscopy (EGA-MS). A kinetic study has been also carried out applying different models to DTA-TG data.

\section{Experimental}

DTA-TG curves were simultaneously carried out at different heating rates on a Setaram high-temperature apparatus (model 92, 16-18). Samples of $30 \mathrm{mg}$ of ATA ( $98 \%$, Riedel) were vacuum outgassed for $30 \mathrm{~min}$, and after this, flowing nitrogen $\left(160 \mathrm{~cm}^{3} / \mathrm{min}\right)$ was held for $30 \mathrm{~min}$. A flow of nitrogen of $16 \mathrm{~cm}^{3} / \mathrm{min}$ was hold during the runs up to $1000^{\circ} \mathrm{C}$. Calcined alumina was used as a reference material and open $\mathrm{Pt}$ crucibles as sample holders.

Evolved gas analysis (EGA) was performed using a Leybold-Heraeus quadrupole Q100 mass spectrometer. This system permits the simultaneous recording, as a function of temperature, of several previously selected $\mathrm{m} / \mathrm{z}$ peaks: 16 (ammonia), 18 (water), 27 (hydrogen cyanide), 28 (nitrogen), 41 and 42. A heating rate of $10 \mathrm{deg} \cdot \mathrm{min}^{-1}$ was used and all the experiments were recorded in vacuum. Mass spectrometry (MS) experiments using solid samples were performed using a Kratos MS80 mass spectrometer operating in electron impact mode. 


\section{Results and discussion}

Figure 1 shows DTA-TG curves corresponding to the organic pesticide ATA. A very sharp and intense endothermic effect at about $160^{\circ} \mathrm{C}$ is observed. It is not accompanied by weight loss since it corresponds to the ATA melting point. A first weight loss of $50.5 \%$ of the initial weight of sample is observed between 220 and $340^{\circ} \mathrm{C}$, although it is significant that this weight loss increases when heating rate decreases. It is related to kinetic features, as will be shown later. The weight loss is associated with several thermal effects on the DTA curve (Fig. 1). There is a moderate endothermic effect at $270^{\circ} \mathrm{C}$, which is more easily observed in the DTA curves performed at lower heating rate (Fig. 2). Very close to this, a very sharp exothermic effect with maximum at $318^{\circ} \mathrm{C}$ is detected. The final temperature of the first weight loss coincides exactly with the final temperature of the later exothermic effect.

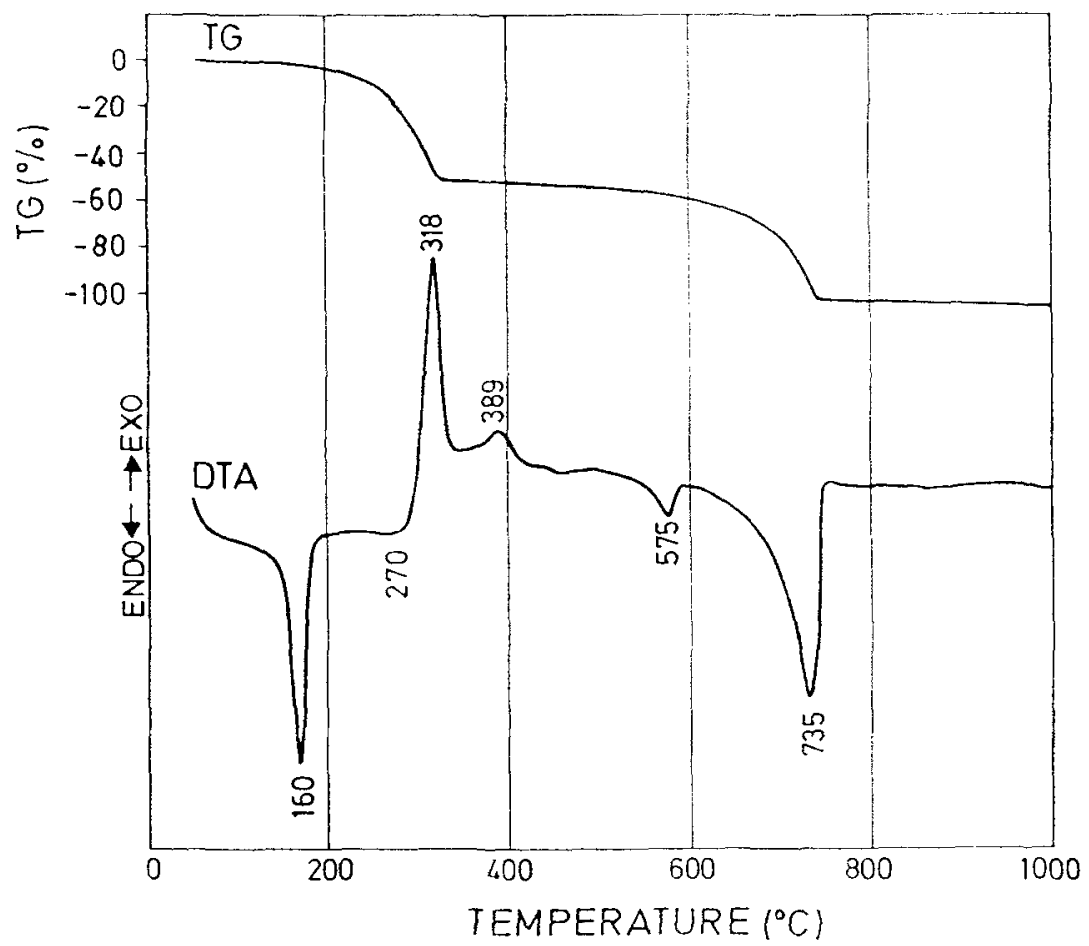

Fig. 1 DTA and TG curves of pure ATA

The products obtained before and after the exothermic peak have been studied by solid mass spectrometry and the evolution of evolved gases, to get an idea about the processes that could originate the first weight loss. The MS analysis of ATA previously heated at $340^{\circ} \mathrm{C}$ (Fig. 3) indicates that a mixture of com- 
pounds is obtained after the first weight loss, with the principal component being a compound of molecular weight 126 , together with ATA (molecular weight 84) without becoming decomposing. The analysis of evolved gases (Fig. 4) shows $\mathrm{N}_{2}, \mathrm{HCN}$ and $\mathrm{NH}_{3}$ liberation in this temperature range, and it can be also observed the release of a gaseous compound of molecular weight 41-42.

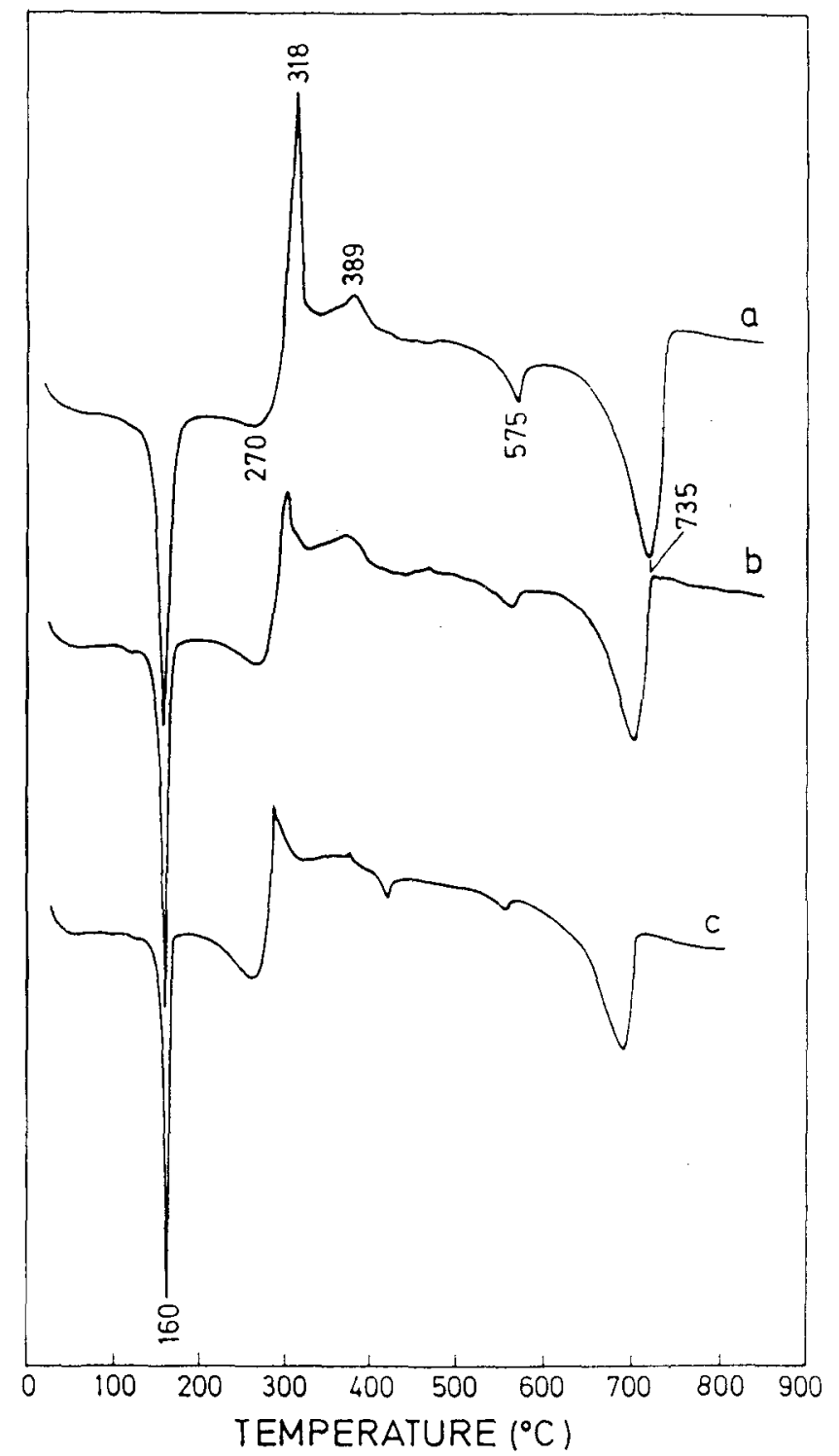

Fig. 2 DTA curves of pure ATA heated at $10(a), 5(b)$ and $2(c)$ deg $\cdot \mathrm{m} \mathrm{in}^{-1}$ 
The exothermic peak at $318^{\circ} \mathrm{C}$ could come from an exothermic reaction forming a more stable compound from other precursors. This could correspond to the formation of the compound of molecular weight 126 . It is assumed that the formation of this compound needs a previous decomposition of pure ATA in some other products, which further react between them to form it. Such decomposition needs energy, so it would explain the presence of the endothermic effect observed at $270^{\circ} \mathrm{C}$. Decomposition products are partially gaseous and their release gives, as a result, the weight loss observed from $220^{\circ} \mathrm{C}$ (Fig. 1). It is assumed that the pesticide decomposition takes place probably following the scheme 2. It gives rise to two resonant forms corresponding to a compound of molecular weight 42 . It coincides with the gaseous compound detected by EGA (Fig. 4). This compound is liberated in part, but another fraction can react with ATA remaining without decomposing, giving rise to the triazole guanidine ( $\mathrm{N}$ (2-triazolin)-guanidine), with molecular weight 126 (Scheme 3). Probably, this compound is that one detected by mass spectrometry (Fig. 3).

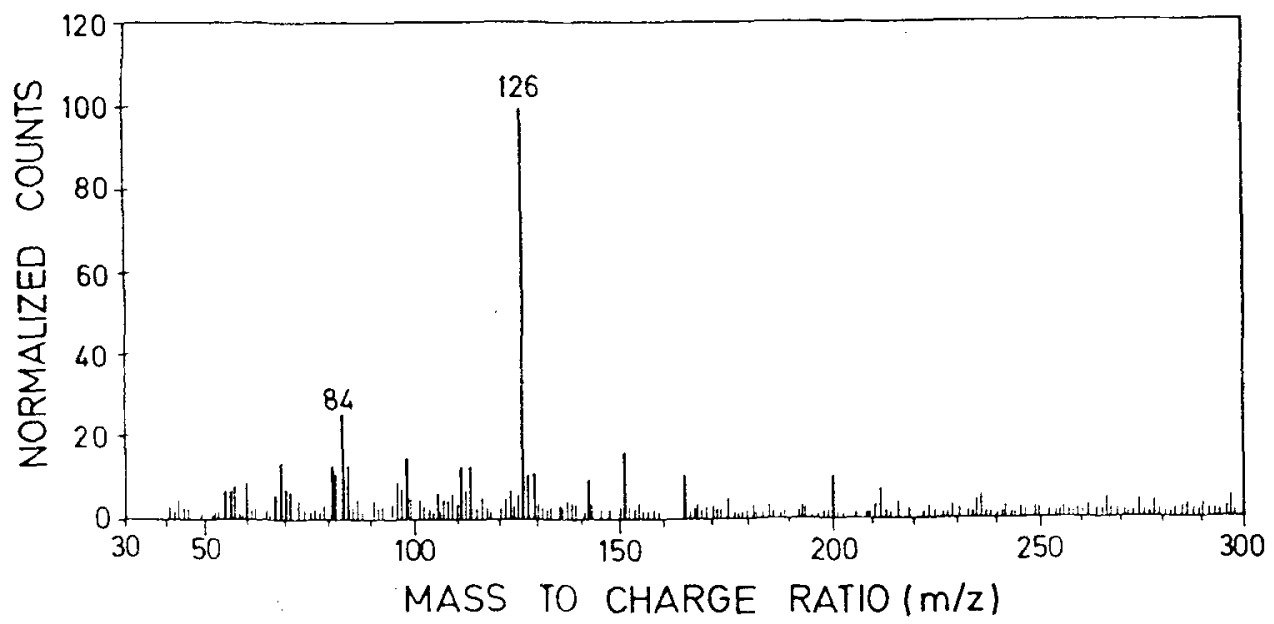

Fig. 3 Mass spectrogram for species present after heating ATA at $340^{\circ} \mathrm{C}$

The exothermic effect at $318^{\circ} \mathrm{C}$ decreases with decreasing heating rates, becoming quite small at $2 \mathrm{deg} \cdot \mathrm{min}^{-1}$ (Fig. 2). It can be associated to the fact that when ATA decomposition temperature is reached, the gaseous decomposition products are liberated until the formation temperature of the new product. This interval of time is longer for low heating rates, allowing to release a higher amount of gas. It is in agreement with the higher weight loss due to gas liberation observed at lower heating rates, in comparison to the higher ones. Then, less amount of the new product of molecular weight 126 can be obtained, and the exothermic effect corresponding to this reaction is detected smaller. 


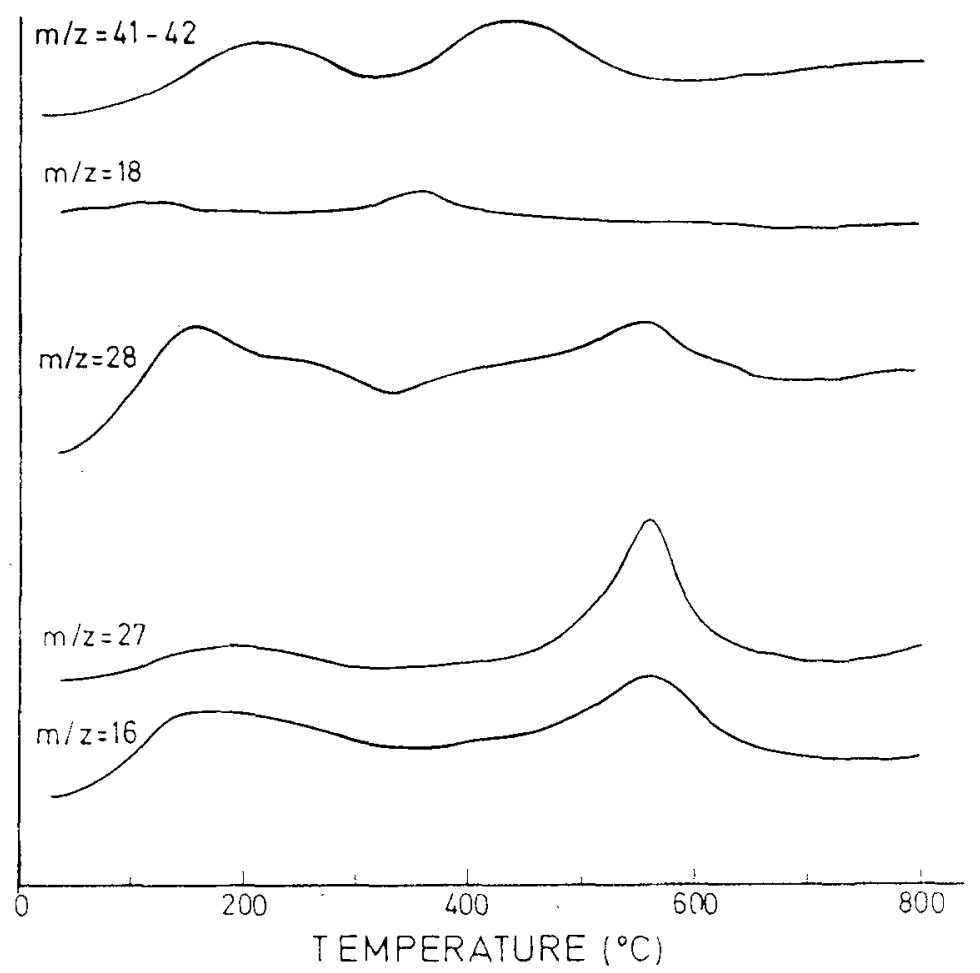

Fig. 4 Gas evolution curves obtained by thermal analysis of pure ATA. Mass peaks $m / z=16$ (ammonia), 18 (water), 27 (hydrogen cyanide), 28 (nitrogen), $41(\times 10)$ and $42(\times 10)$

Scheme 2

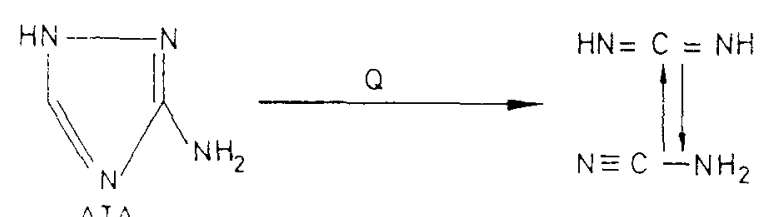

Scheme 3

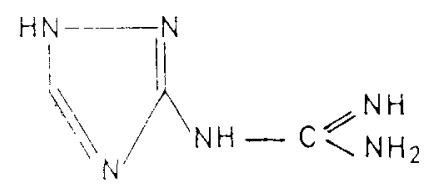

From $340^{\circ} \mathrm{C}$ and above, very little weight loss is observed until reaching $600^{\circ} \mathrm{C}$. At this temperature the total decomposition of the organic products takes place. The evolution of a great amount of gases such as $\mathrm{N}_{2}, \mathrm{HCN}, \mathrm{H}_{2} \mathrm{O}$ and $\mathrm{NH}_{3}$ 
is observed in the EGA curves (Fig. 4). This total decomposition is accompanied by an endothermic effect with maximum at $735^{\circ} \mathrm{C}$ and after this point, the decomposition finishes. The weight loss obtained during the ATA heating and subsequent degradation process is $96 \%$.

The first stage of ATA decomposition (between $220-340^{\circ} \mathrm{C}$ ) has been kinetically analyzed because the thermal stability of ATA seems to be dependent on the kinetic parameters of this first stage, as found in other systems [3]. The Ozawa's method [4] has been used to determine the activation energy from plots of the logarithms of heating rates $(\beta) v s$. the inverse of temperature at a given conversion (from $\alpha=0.2$ to 0.8 ), as shown in Fig. 5. The activation energy was calculated from the average value for the different conversions, resulting a value of $E_{\mathrm{a}}=124 \pm 8 \mathrm{~kJ} \cdot \mathrm{mol}^{-1}$. The Kissinger's method [5] was also applied. A plot of $\ln \left(\beta / T_{\mathrm{p}}^{2}\right) v$ s. $1 / T_{\mathrm{p}}$, being $T_{\mathrm{p}}$ the DTA peak temperature, is shown in Fig. 6. A value of $E_{\mathrm{a}}=140 \pm 8 \mathrm{~kJ} \cdot \mathrm{mol}^{-1}$ was obtained in well agreement with the value obtained applying the Ozawa's method.

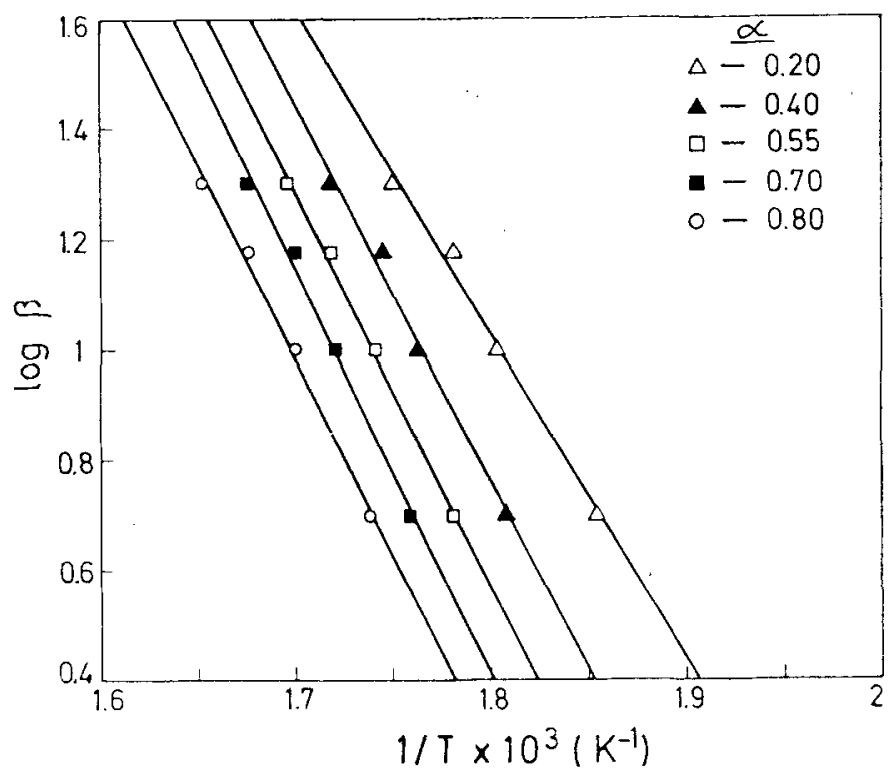

Fig. 5 Ozawa's plot of $\log \beta$ vs. the reciprocal of temperature $(\alpha=0.2-0.8)$

Furthermore, the results obtained from kinetic analysis of these curves in the range of conversion $0.2<\alpha<0.8$ by means of the Coats and Redfern method [6], taking into account different $g(\alpha)$ functions, have been included in Table 1. A comparison of these results with those previously obtained by Ozawa and Kissinger methods' showed that a reasonable well agreement between the activation energies obtained from both methods can be achieved only if it is as- 


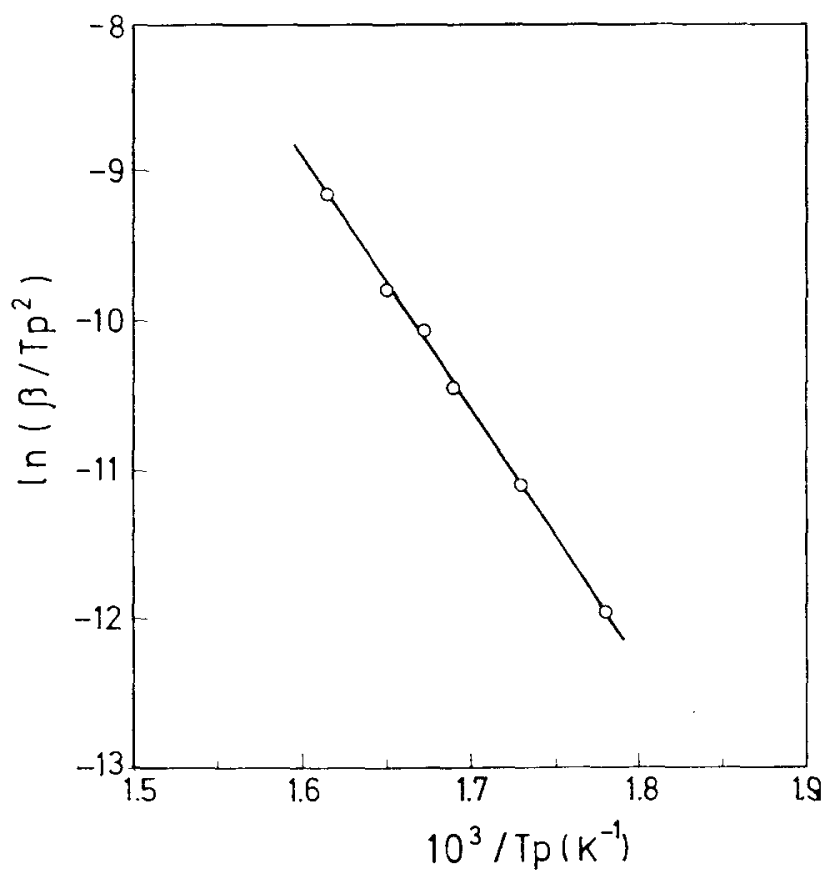

Fig. 6 Kissinger's plot of $\ln \left(\beta / T_{\mathrm{p}}^{2}\right)$ vs. the reciprocal of the DTA peak temperature

Table 1 Kinetic parameters and correlation coefficients corresponding the first stage of ATA decomposition, calculated by means of the Arrhenius equation $\left(\beta=10 \mathrm{deg} \cdot \mathrm{min}^{-1} ; \alpha=\right.$ $0.10,0.25,0.40,0.55,0.70,0.85 ; T=533,554,567,574,581,588 \mathrm{~K})$

\begin{tabular}{crrr}
\hline Mechanism & $E / \mathrm{kJ} \cdot \mathrm{mol}^{-1}$ & \multicolumn{1}{c}{$A / \mathrm{s}^{-1}$} & \multicolumn{1}{c}{} \\
\hline $\mathrm{R}_{1}$ & $92.6 \pm 1.7$ & $5.9 \pm 0.37$ & 0.9993 \\
$\mathrm{R}_{2}$ & $107.3 \pm 2.8$ & $7.4 \pm 0.59$ & 0.9987 \\
$\mathrm{R}_{3}$ & $112.8 \pm 4.1$ & $7.9 \pm 0.86$ & 0.9974 \\
$\mathrm{~F}_{1}$ & $124.6 \pm 7.2$ & $9.1 \pm 1.52$ & 0.9935 \\
$\mathrm{~A}_{1.5}$ & $80.0 \pm 4.7$ & $4.9 \pm 1.01$ & 0.9931 \\
$\mathrm{~A}_{2}$ & $57.7 \pm 3.5$ & $2.8 \pm 0.75$ & 0.9926 \\
$\mathrm{~A}_{2.5}$ & $44.3 \pm 2.8$ & $1.4 \pm 0.60$ & 0.9920 \\
$\mathrm{~A}_{3}$ & $35.4 \pm 2.4$ & $0.5 \pm 0.50$ & 0.9912 \\
$\mathrm{~A}_{4}$ & $24.2 \pm 1.7$ & $-0.7 \pm 0.37$ & 0.9898 \\
$\mathrm{D}_{1}$ & $194.5 \pm 3.3$ & $15.2 \pm 0.70$ & 0.9994 \\
$\mathrm{D}_{2}$ & $212.6 \pm 3.5$ & $16.7 \pm 0.75$ & 0.9995 \\
$\mathrm{D}_{3}$ & $234.9 \pm 8.2$ & $18.3 \pm 1.74$ & 0.9976 \\
$\mathrm{D}_{4}$ & $220.0 \pm 4.9$ & $16.8 \pm 1.03$ & 0.9990 \\
\hline
\end{tabular}


sumed that the thermal decomposition of ATA fits on F1 kinetic model. Moreover, this result is in excellent agreement with the value of $n=1$ and $E_{\mathrm{a}}=130 \mathrm{~kJ} \cdot \mathrm{mol}^{-1}$ obtained from the Freeman and Carroll [7] method.

$$
\text { * * * }
$$

This work was supported by the CICYT (project No. AMB92-0394). We thank Dr. M. A. Pradera for the MS data, and Dr. J. M. Llera for his suggestions.

\section{References}

1 E. Morillo, J. L. Pérez-Rodríguez and C. Maqueda, Clay Miner., 26 (1992) 269.

2 A. Lukasiewicz, J. Michalik, J. Mikosz, L. Walis and I. Wozniak, Mater. Lett, 14 (1991) 127.

3 M. Kamimoto, R. Sakamoto, Y. Takahashi, K. Kanari and T. Ozawa, Thermochim. Acta, 74 (1984) 281.

4 T. Ozawa, Bull. Chem. Soc. Japan, 38 (1965) 1881.

5 H. E. Kissinger, J. Res. Nat. Bur. Stand., 57 (1956) 217.

6 A. W. Coats and J. P. Redfern, Nature, 208 (1964) 68.

7 E. S. Freeman and B. Carroll, J. Phys. Chem., 62 (1958) 394.

Zusammenfassung - Vorliegend wird unter Einsatz simultaner DTA-TG im Stickstofffluß eine thermoanalytische Untersuchung des Pestizides 3-Amino-1,2,4-triazol (ATA) durchgeführt, um dessen thermisches Verhalten und Stabilität zu bestimmen. Diese Techniken wurden weiterhin durch Analyse der freigesetzten Gase und durch Massenspektroskopie (EGA-MS) ergänzt. Es wurden zwei verschiedene Schritte der Zersetzung von ATA beobachtet: nach dem ersten Zersetzungsschritt erhält man ein Verbindungsgemisch, wobei die Hauptkomponente laut MS-Angaben das Molekülgewicht 126 besitzt. Sie wird in einer Reaktion erster Ordnung gebildet, $E_{\mathrm{a}}$ beträgt laut kinetischer Untersuchung $1248 \mathrm{~kJ} / \mathrm{mol}$. Der zweite Zersetzungsschritt findet unter Freisetzung von $\mathrm{HCN}$ und $\mathrm{NH}_{3}$ bei etwa $735^{\circ} \mathrm{C}$ statt, der endgültige Gewichtsverlust beträgt $96 \%$. 